\title{
Teleauscultation: Bringing you to the bedside
}

\author{
HANS PASTERKAMP MD FRCPC, IGNACIO SANCHEZ MD, YUNS OH MScEE \\ Department of Pediatrics and Child Health, University of Manitoba, Winnipeg, Manitoba
}

H Pasterkamp, I Sanchez, Y OH. Teleauscultation: Bringing you to the bedside. Can Respir J 1995; 2(4):237-240.

A cuslom-made device was used for the acquisition, digitization, compression, storage and telephone transmission of respiratory sounds and airflow data. Acoustical information from two patients at a small community in rural Manitoba was sent over a distance of $500 \mathrm{~km}$ via conventional telephone lines. Digital transmission left the respiratory sounds unaffected by telephone line noise. Data processing by computer at the receiving site provided more detail than would have been available on conventional auscultation. This new method for teleauscuitation could be of value not only in remote areas but also for the surveillance of patients at home in urban settings.

Key Words: Diagnestic terhniques, Respiratory somnds, Telemedicine

\section{La téléauscultation vous amène au chevet du patient}

RÉSUMÉ : Un appareil fabriqué sur commande a été utilisé pour I'acquisition, la numérisation, la concentration, le stockage et la transmission par téléphone de données sur les bruits respiratoires et l'écoulement de l'air. L'information acoustique provenant de deux patients d'une petite communauté rurale du Manitoba a été transmise sur une distance de $500 \mathrm{~km}$ par les lignes téléphoniques classiques. La transmission numérique a permis aux bruits pulmonaires de ne pas être altérés par les bruits de fond de la ligne téléphonique. Le traitement des données par ordinateur sur le lieu de réception a fourni plus de détails qu'une auscultation classique n'aurait pas pu fournir. Cette nouvelle méthode pour la téléauscultation pourrait être utile non seulement dans les endroits éloignés mais aussi pour la surveillance des patients à domicile en milieu urbain.

\begin{abstract}
A USCULTATION REMAINS IMPORTANT FOR THE DIAGNOSIS of chest diseases although techniques that provide numerical and visual data are favoured for reasons of objectivity. Information obtained with a stethoscope is typically conveyed as a subjective interpretation, but sharing the original acoustical perception with others can become important in the case of diagnostic uncertainty. Communication of respiratory sounds via telephone has been successful, both ad hoc by simply placing the receiver on the patient's chest $(1,2)$
\end{abstract}

and in formal testing using an electronic stethoscope connected to the telephone line (3). However, the low frequency characteristics of respiratory sounds make them difficult to transmit using conventional telephone connections, which are optimized for higher frequency speech communication (4). Telephone line noise can obscure and corrupt the respiratory sound signal, and the interpretation on the receiving side remains subjective. This mode of teleauscultation, although it has been recognized as "the next best thing to being

Correspondence and reprints: Dr Hans Pasterkamp. Section of Respirology, Department of Pediutrics and Child Health, CN503-\$2t) Sherbrok Street, Winnipeg. Manitoba R3A ISI.Telephone204-787-4753.Fax 204-787-1018.e-mail:h_pustrkamp@umanitoha.ca 

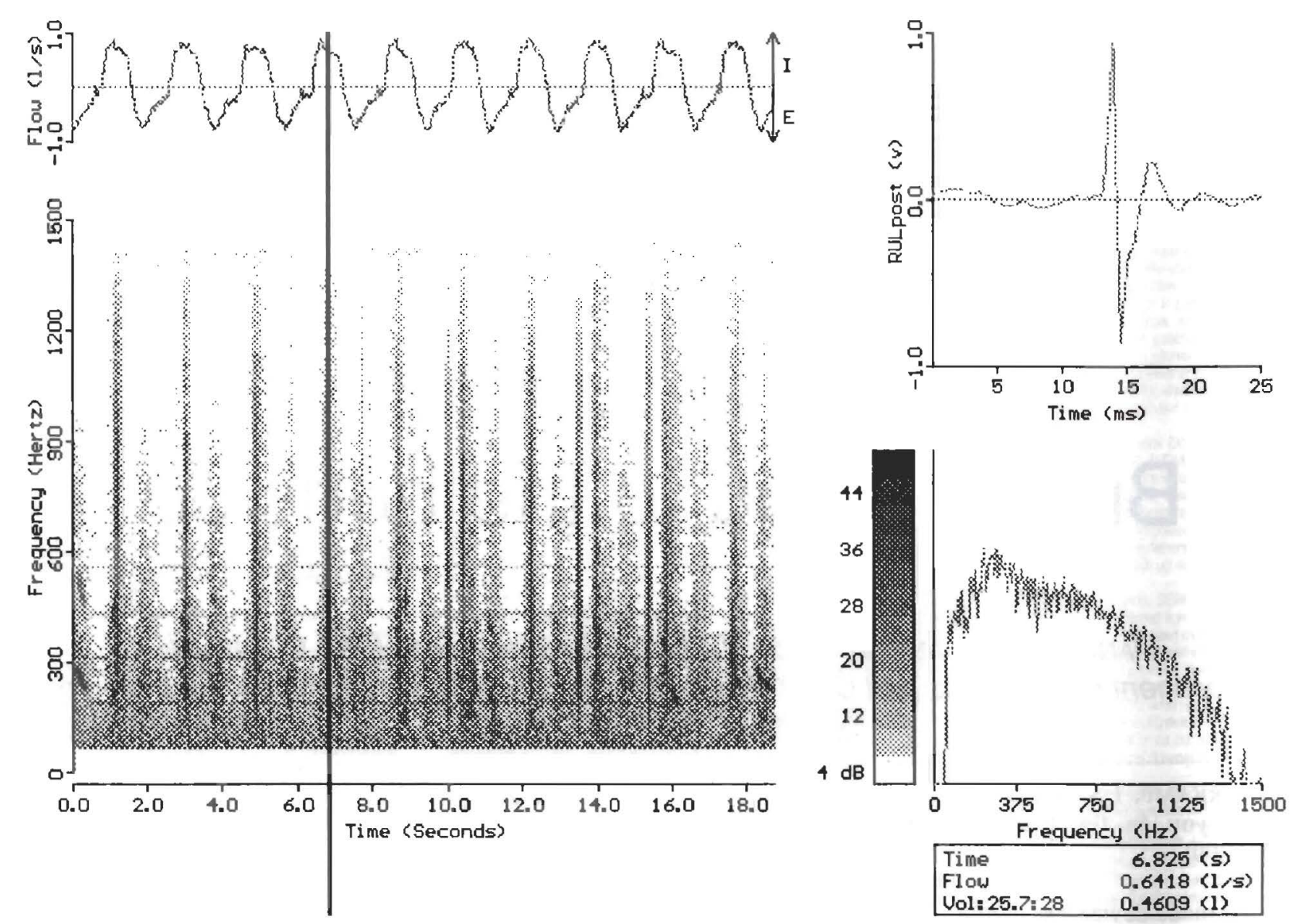

Figure 1) Transmitted data from case 1 . Airflum is at the top $(l=$ inspiration, $E=$ expiration $)$. Sound intensity is indicated on a grey scale. The vertical bar in the sonogram (left) at 6.9 s points to a selected $25 \mathrm{~ms}$ of sound which is shown as a time-amplitude plot (top right), with the corresponding Fourier spectrum (bottom right). Sound below $100 \mathrm{~Hz}$ was removed by digital filtering for an improved display of crackles,

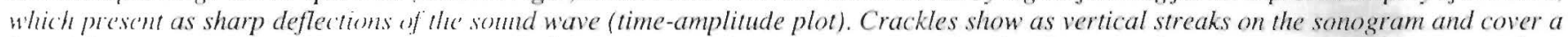

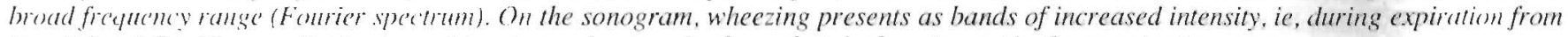
time $0.1 \omega 0.5$. The pallel horizond bands are due to noise from electrical equipment in the examination room

there" (I), offers no more than a poorly designed stethoscope to an examiner at a distance. We describe the use of a device for acquisition and telecommunication of respiratory acoustical and airflow signals in digital format. We present the processing of transmitted datit by computer and discuss potential clinical applications.

\section{PATIENTS AND METHODS}

A small. battery operated device for acquisition, digitizaltion. compression, storage and transnission of respiratory sounds and airflow data was developed. Technical details of this device have been reported elsewhere (5). An accelerometer (6) is uscol as the sound sensor (EMT 25C, Siemens. New Jersey) and airflow is recorded with a calibrated pneumotachograph (Fleisch No 3 with pressure transducer, Validyne, California). The digitized sound and airflow signals are transmitted via 2400 baud nnodem from remote locations to the Acoustics Laboratory at the Children's Hospital in Winnipeg. Here they are processed on an IBM compatible personal computer, using a custom written software package
(R.A.L.E.) as previously reported (7). This method was tested during a visit by two of the authors to the Garden Hill First Nations Community, approximately $500 \mathrm{~km}$ northeast of Winnipeg. Communication was over conventional long distance analogue telephone lines. Two patients at the local nursing station, a 67-year-old woman with pulmonary librosis and bronchiectasis after tuberculosis, and a 25 -year-old woman with acute asthma, gave their consent to participate after they were informed about the nature and purpose of the test. The sound sensor was attached over the posterior right chest. Wearing a noseclip, the patients breathed through the pneumotachograph at their own rate and depth. The quality of respiratory sound data on digital-to-analogue playback from the portable device was listened to before transmission.

\section{CASE OBSERVATIONS}

Respiratory sounds at the right upper lobe of the patient with pulmonary fibrosis contained inspiratory and some expiratory crackles as well as occasional brief wheezes (Figure I). Total recording lime was $18.8 \mathrm{~s}$. Compression reduced the 

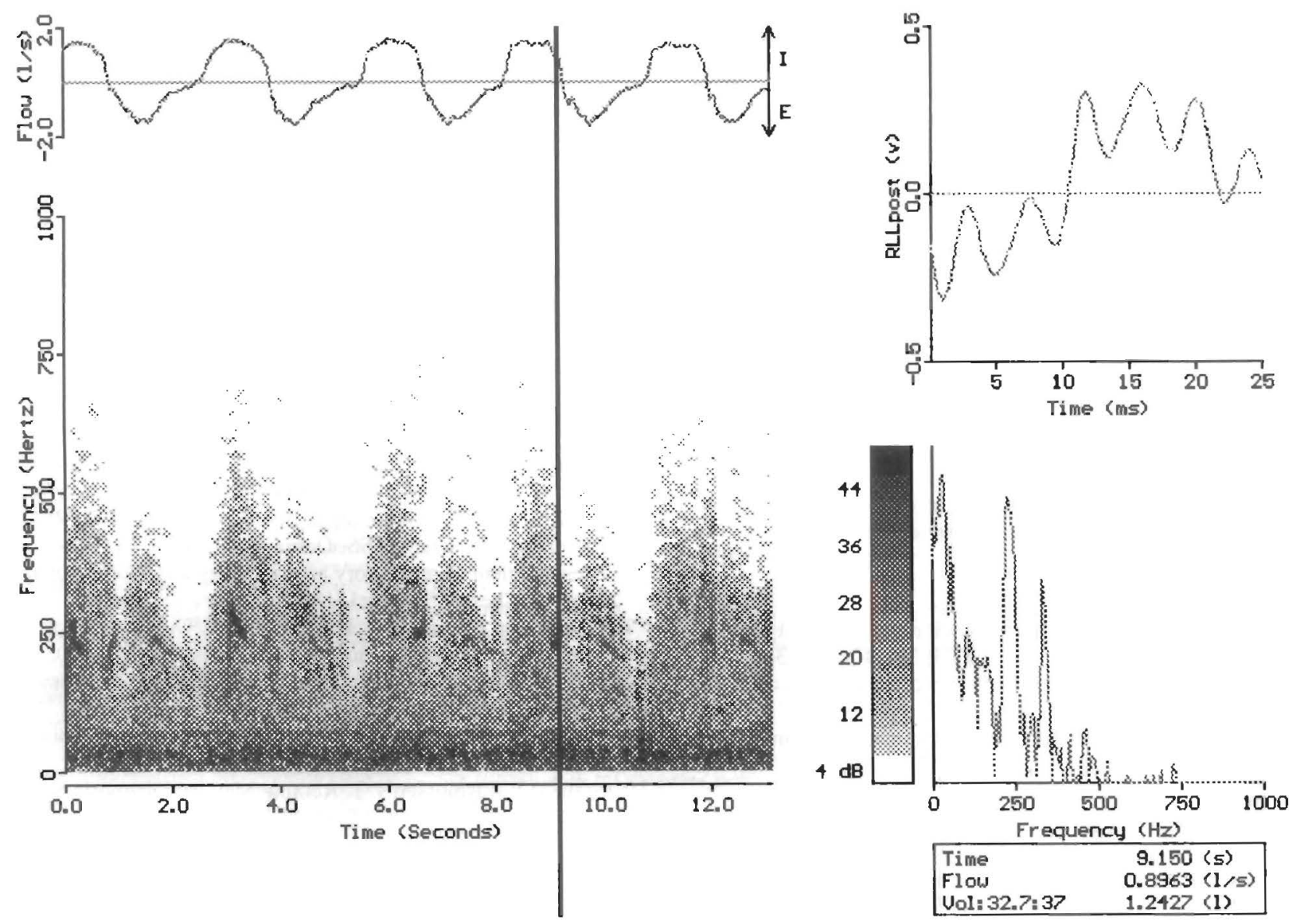

Figure 2) Data transmitted from case 2. The vertical bar at 9.15 s points to a selected 25 ms of sound (left) which is shown as a time-amplitude plot (top right), with the corresponding Fourier spectrum (bottom right). Sound below $100 \mathrm{~Hz}$ was removed by digital filtering for an improved display of crackles, which present as sharp deflections of the sound wave (time-amplitude plot). Crackles show as vertical streaks on the sonogram and cover a broad frequency range (Fourier spectrum). Wheezes present as sinusoidal sound waves (top right) with sharp peaks in the power spectrum (bottom right). The sonogram shows wheezes as bands of increased intensity, in this case most prominent during inspiration

data size by $43 \%$ to 65 kbytes before transmission. From the airflow signal, the respiratory rate was estimated as $33 / \mathrm{min}$, with an inspiration:expiration ratio of 1:1.75, a mean inspiratory flow of $0.6 \mathrm{~L} / \mathrm{s}$ and an average tidal volume of $0.5 \mathrm{~L}$. The sounds recorded at the posterior right upper lobe of the patient with asthma contained wheezes during inspiration and expiration (Figure 2). Total recording time was $13.1 \mathrm{~s}$. Compression reduced the data size by $41 \%$ to 44 kbytes before transmission. The respiratory rate was $22 / \mathrm{min}$, with an inspiration:expiration ratio of $1: 1.72$, a mean inspiratory flow of $1.1 \mathrm{~L} / \mathrm{s}$, and an average tidal volume of $1.3 \mathrm{~L}$. The frequency bandwidth of normal lung sounds in this recording, calculated after exclusion of parts that contained wheeze, extended from below $100 \mathrm{~Hz}$ to above $500 \mathrm{~Hz}$, with a maximum signal-to-noise ratio greater than $20 \mathrm{~dB}$ (Figure 3). The average data transmission rate was $0.2 \mathrm{kbytes} / \mathrm{s}$, resulting in transmission times of approximately 6 mins for the first and 4 mins for the second recording. Because of interrupted telephone connections, several attempts were necessary for transmission of the second data file.

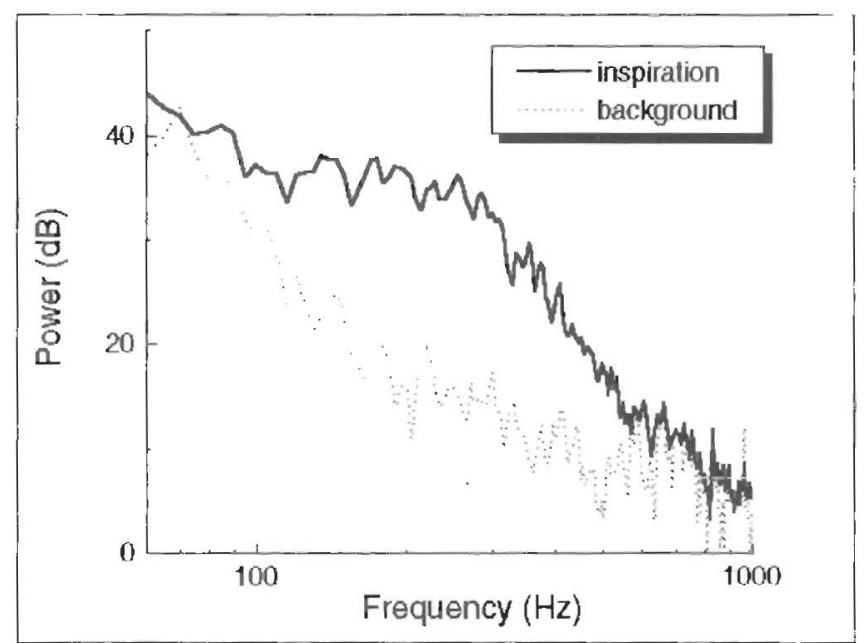

Figure 3) Average power spectrum of inspiratory sounds at airflow $1.2 \pm 0.2 \mathrm{~L} / \mathrm{s}$, plotted against average background noise, obtained during end-expiration at airflow $0.2 \pm 0.1 \mathrm{~L} / \mathrm{s}$ (case 2). The use of average lung sound spectra at standardized air flows provides reproducible and valuable information about breath sound intensity (ie, sisnat-to-noise ratio) and quality (ie, spectral shape and bandwidth) 


\section{DISCUSSION}

Canada has been a world leader in developing communication systems and in their application to health care (8). Almost 20 years ago, transmission of low frequency body sounds was already part of a satellite link between the Moose Factory hospital and Kashechewan nursing station with the University of Western Ontario in London, Ontario (10). A system for remote medical diagnosis, described in 1982 for use on navy ships, transmitted auscultatory data via telephone at the same speed as in our study (10). The latest high-speed modems would have reduced transmission timc by a factor of six or more. Innovations in telecommunications will rapidly change this situation, providing an increase of speed by orders of magnitude. Digital transmission

ACKNOWLEDGEMENTS: Dr Sanchez was a Fellow of the Manitoba Lung Association. This study was supported by the Children's Hospital of Winnipeg Research Foundation.

\section{REFERENCES}

1. Fallis G, Casson I, Orser B. "Teleauscultation": the next best thing to being there. Can Med Assoc J 1989;140:1129-31.

2. Karr MD. Just reach out and percuss someone. JAMA 1992;268:604. (Lett)

3. Bhat K, Scott PH, Eigen H, Boggs PB. Evaluation of lung sounds by telephonc. Ann Allergy 1985;54:109-1 I.

4. McNamara JE. Technical Aspects of Data Communications. 2nd cdn. Bedford: Digital Press, 1982:292-5. of respiratory sounds assures immunity from noise on the telephone line. Data processing by computer as reported herein can provide more detail than would be recognized on conventional auscultation. There are circumstances where this new technique for teleauscultation could be of benefit not only to observers at remote locations who want an expert opinion. We see a potential application for longitudinal surveillance at home, particularly of patients whose diagnosis is based on the perception of respiratory sounds, such as in wheezy infants. Other critical informiltion, including patient behaviour, skin colour, respiratory effort, etc, has to be communicated separately. Keeping this limitation in mind, teleauscultation may now be ats good as being there.

5. Oh Y, Pasterkamp H. Acquisition and telecommunication of physiologic variables with a portable device. Proceedings of the 1991 CMBES Conference, Banff, Alberta, 1991:89-90.

6. Pasterkamp H, Kraman SS, DeFrain PD, Wodicka GR. Measurement of respiratory acoustical signals. Comparison of sensors. Chest 1993;104:1518-25.

7. Pasterkamp H, Carson C, Daien D, Oh Y. Digital respirosono graphy. New images of lung sounds. Chest 1989;96:1405-I2.

8. Dunn EV, Higgins CA. Telemedicine in Canada: an overvicw. Dimens Health Serv 1984;61:16-8.

9. Sophianopoulos A, Mills M. Medicine in the north: a unique experiment. Telesis 1976;4:258-62.

10. Stevens I, Rasmussen WT. Remote Medical Diagnosis System (RMDS) concept. J Med Syst 1982;6:519-29. 


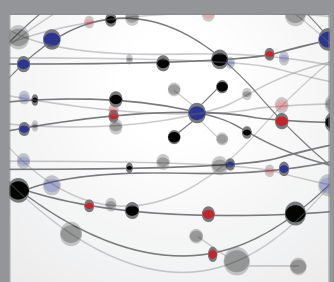

The Scientific World Journal
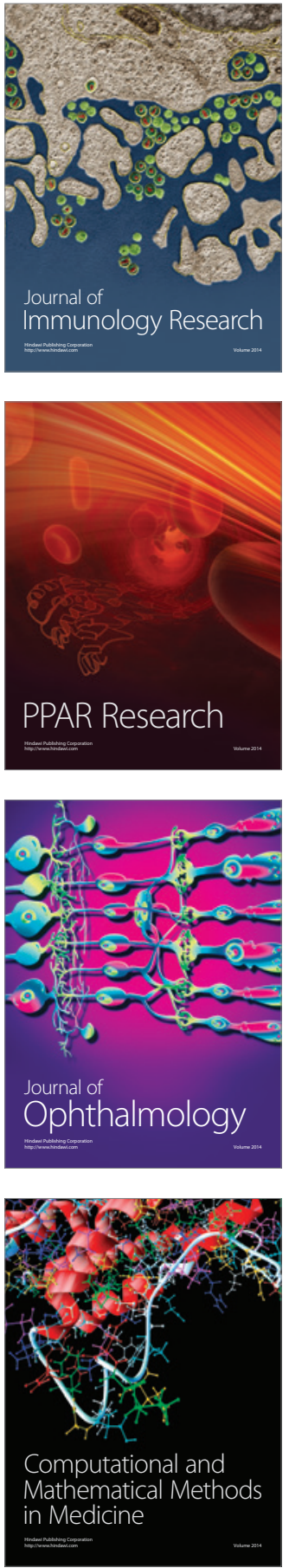

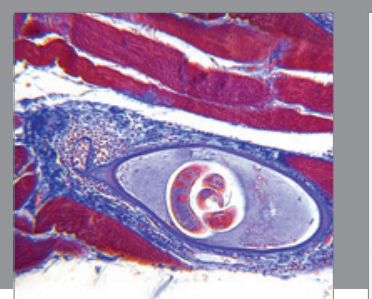

Gastroenterology Research and Practice

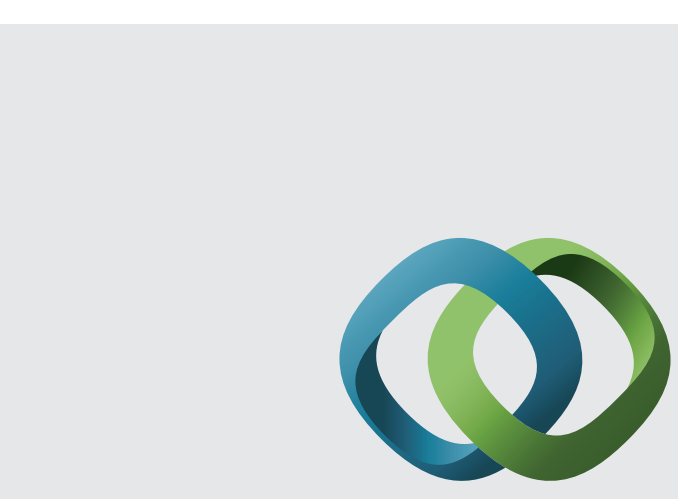

\section{Hindawi}

Submit your manuscripts at

http://www.hindawi.com
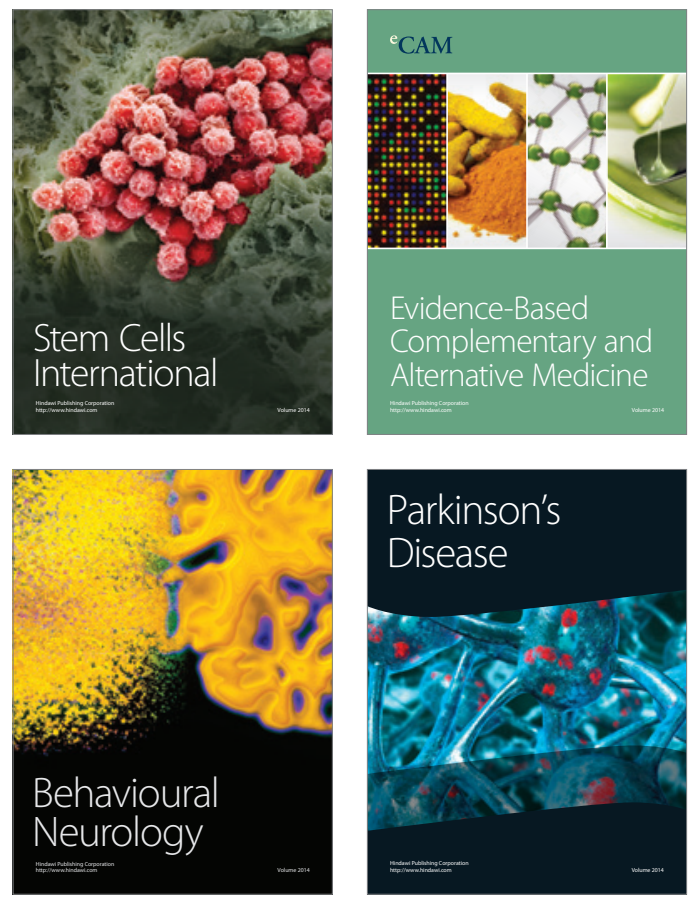
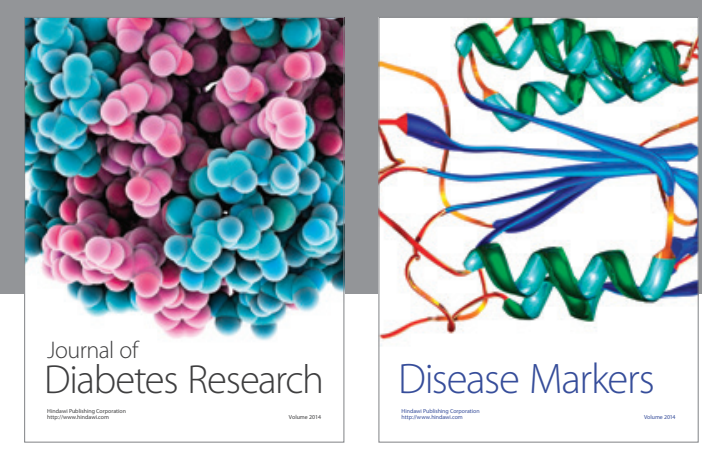

Disease Markers
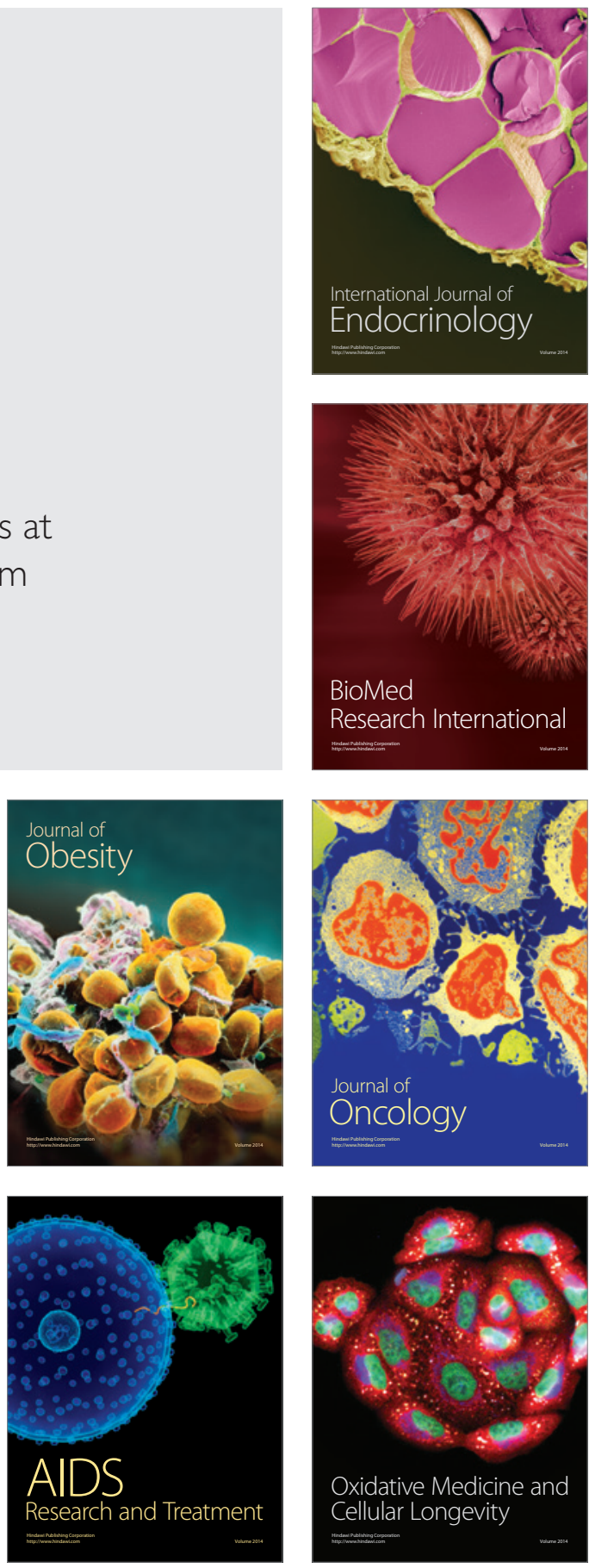